\title{
Nano-alloys synthesized by controlled crystallization from supercooled atomic clusters of elements
}

\author{
X.K. Meng \\ National Laboratory of Solid State Microstructures and Department of Materials \\ Science and Engineering, Nanjing University, Nanjing 210093, People's Republic of China \\ A.H.W. Ngan ${ }^{\text {a) }}$ \\ Department of Mechanical Engineering, The University of Hong Kong, \\ Hong Kong, People's Republic of China
}

(Received 10 June 2003; accepted 10 November 2003)

\begin{abstract}
Materials in nanocrystalline forms are well known to possess unusual and interesting properties when compared to the bulk conditions, and these open up an exciting range of novel applications. The key step involved in the systematic exploitation of nanocrystals for real applications lies in the development of reliable methods to synthesize nanocrystals of arbitrary chemical compositions in a range of crystal sizes. In particular, metallic alloy nanocrystals pose a special challenge. We demonstrate that nano-to-micro-sized crystals of intermetallic nickel-aluminide $\left(\mathrm{Ni}_{3} \mathrm{Al}\right)$ ranging from approximately $3 \mathrm{~nm}$ to over $100 \mathrm{~nm}$ in size can be synthesized by co-sputtering from elemental $\mathrm{Ni}$ and $\mathrm{Al}$ onto unheated, incompatible organic substrates, followed by controlled postdeposition heat treatment at mild temperatures. The crystal size of approximately $3 \mathrm{~nm}$ here is the smallest ever reported for monolithic ordered $\mathrm{Ni}_{3} \mathrm{Al}$.
\end{abstract}

\section{INTRODUCTION}

In recent years, nanostructured metallic alloys have been demonstrated to exhibit a range of interesting properties $^{1-3}$ for novel applications such as, for example, superplastic materials, ${ }^{4}$ catalysts, ${ }^{5,6}$ soft magnets, ${ }^{7-9}$ thermal-electrical sensors, ${ }^{10}$ gas sensors and hydrogenstorage materials, ${ }^{11}$ structural components for micronano devices, ${ }^{12}$ shape memory materials, ${ }^{13}$ and so forth, and it is highly likely that many more novel properties can be found from metallic alloy nanocrystals (MANCs) if more systematic investigations can be carried out. This calls for the development of generic methods to synthesis MANCs with chemical compositions chosen at will. Traditional means of synthesizing nano-sized powders such as electrochemical or precipitation reactions ${ }^{14}$ are often material specific, and their applicability to MANCs with arbitrary, yet predetermined chemical compositions is rather limited. The method of solid-state precipitation by aging a supersaturated solid solution can produce nanosized precipitates, ${ }^{1}$ but such nanocrystals are embedded in a matrix and not in monolithic form, and the applicability is also limited to systems with suitable phase separation and solidus curvature. A technique using pulsedlaser vaporization and condensation has successfully

\footnotetext{
a) Address all correspondence to this author. e-mail: hwngan@hku.hk
}

been used to produce nanocrystals of the B2 intermetallic $\mathrm{FeAl},{ }^{15,16}$ but applicability to a wide range of MANCs has not yet been established.

\section{EXPERIMENTAL}

In this work, we demonstrate the possibility of using magnetron cosputtering on cold, incompatible substrates, followed by controlled annealing in ultrahigh vacuum to synthesize MANCs. The key is to produce a highly supercooled but microscopically homogeneous state of the required chemical composition by co-sputtering, and MANCs can then be grown out from such a far-fromequilibrium state by controlled annealing in ultrahigh vacuum. Amorphization of metals can be carried out by several means including physical, chemical, or electronbeam vapor deposition, rapid solidification such as meltspinning, irradiation, hydrogen absorption, mechanical alloying, and so forth. ${ }^{17} \mathrm{We}$ select the physical vapor deposition technique of co-sputtering here because the applicability of this method is perhaps the least dependent on the material system.

We choose the intermetallic alloy $\mathrm{Ni}_{3} \mathrm{Al}$ as a prototype material system for investigation here. $\mathrm{Ni}_{3} \mathrm{Al}$ in the bulk form is a representative Berthollide intermetallic ${ }^{18}$ that remains ordered with the Strukturbericht $-\mathrm{L}_{2}$ structure, which is an ordered face-centered-cubic (fcc) structure, up to melting at $1362{ }^{\circ} \mathrm{C}$. In the bulk condition, it exists within a phase width from approximately 73 to 
approximately 77 at.\% of Al. Sputter-deposited nanocrystalline $\mathrm{Ni}_{3} \mathrm{Al}$ thin films have also been found to exhibit interesting physical properties. Oxygencontaining nanocrystalline $\mathrm{Ni}_{3} \mathrm{Al}$ was found to exhibit a sharp metal-to-insulator transition as temperature is lowered. ${ }^{10}$ Nanocrystalline $\mathrm{Ni}_{3} \mathrm{Al}$ is also known to exhibit zero strain-rate sensitivity of strength ${ }^{19}$ and superplasticity at a temperature several hundred degrees lower than that in the microcrystalline counterpart. ${ }^{4}$ Amorphization of $\mathrm{Ni}_{3} \mathrm{Al}$, on the other hand, is difficult. ${ }^{20}$ Ball milling could only disorder $\mathrm{Ni}_{3} \mathrm{Al}$ into the $\gamma$-fcc structure and produce partial amorphization upon long milling times, but not full amorphization. ${ }^{21,22}$ Hot pressing following mechanical alloying of elemental powders ${ }^{23}$ can produce nanocrystalline $\mathrm{Ni}_{3} \mathrm{Al}$, but contamination during ball milling remains a difficult problem to solve. ${ }^{23,24}$ Previous rapid solidification experiments by laser pulse irradiation also did not produce a glassy state of $\mathrm{Ni}_{3} \mathrm{Al}$ but could only disorder it. ${ }^{25}$ Molecular dynamics simulations ${ }^{26}$ have indeed predicted that the cooling rate required to produce a glassy state of $\mathrm{Ni}_{3} \mathrm{Al}$ from melt is far too high to be achievable in experimental conditions, thus ruling out rapid solidification techniques as an alternative to produce an initial glassy state for subsequent aging.

In this work, $\mathrm{Ni}-\mathrm{Al}$ thin films with composition of 75 at.\% Ni and 25 at.\% $\mathrm{Al}$ were prepared by direct current $(\mathrm{dc})$ magnetron co-sputtering using a $\mathrm{Ni}-\mathrm{Al}$ multitarget. To form the multitarget, high purity $\mathrm{Ni}$ and $\mathrm{Al}$ (99.5\%) sheets were cut into $10^{\circ}$ sectors and were glued together to form a circular disk. Our previous experience $^{27}$ shows that the exact $3 \mathrm{Ni}: 1 \mathrm{Al}$ composition can be achieved in the deposited film by using an area ratio of $23 \mathrm{Ni}: 13 \mathrm{Al}$ (36 sectors in total) in the multitarget. Such a ratio is lower than the nominal 3:1 because of the unequal sputtering yields and re-evaporation rates of $\mathrm{Ni}$ and $\mathrm{Al}$. The sputtered film composition was confirmed to be $74.9 \% \mathrm{Ni}: 25: 1 \% \mathrm{Al}$ by energy dispersive $\mathrm{x}$-ray analysis. The co-sputtering deposition was performed in a JCK-500A dc magnetron sputtering system under an Ar pressure of $1 \times 10^{-2}$ mbar. The sputtering process lasted typically for $54 \mathrm{~s}$ at a deposition rate of $1.1 \mathrm{~nm} / \mathrm{s}$ under the sputtering conditions of $60 \mathrm{~W}$ and $350 \mathrm{~V}$ at room temperature. To ensure a high degree of supercooling, low adatom mobility is required and for this reason, an incompatible substrate of a thin membrane of a mixture of $2 \%$ collodion and $98 \%$ isoamyl acetate was used. The organic membrane was gelatinized onto a copper grid for efficient thermal extraction to keep the substrate cool as well as for mechanical support. Postdeposition annealing was done inside a JEOL (Tokyo, Japan) JEM-200CX transmission electronic microscope operating at $200 \mathrm{kV}$ to allow in situ observation. The vacuum inside the transmission electronic microscope was maintained at a condition better than $10^{-6}$ mbar. The samples were heated up to a terminal temperature of $750{ }^{\circ} \mathrm{C}$ or $800{ }^{\circ} \mathrm{C}$ by steps of $100{ }^{\circ} \mathrm{C}$ and then cooled in vacuum. At each heating step, the temperature was held for $30 \mathrm{~min}$ before being raised to the next higher value to prevent excessive film-substrate interfacial stresses to delaminate the film, as well as to allow time for dynamic observation. The experiment was repeated using five different samples, and a high degree of consistency in the annealing behavior was found among these. The presence of the polymer film can be detected in the transmission electronic microscope by the semitransparent bright-field contrast in areas not covered by the metals. It was generally observed that the polymer film began to evaporate at approximately $300{ }^{\circ} \mathrm{C}$.

\section{RESULTS AND DISCUSSION}

Figure 1 shows the as-deposited state of a very thin area of a 75 at.\% Ni-25 at.\% film. The bright-field image in Fig. 1 shows nano-sized regions exhibiting black/white contrast. The selected area diffraction pattern (SADP) in the inset of Fig. 1 shows a series of diffused annular bands, superimposed on a radially decaying, bremsstrahlung-like background characteristic of inelastic scattering. The average radii of the annular bands coincide well with the diffraction rings expected from
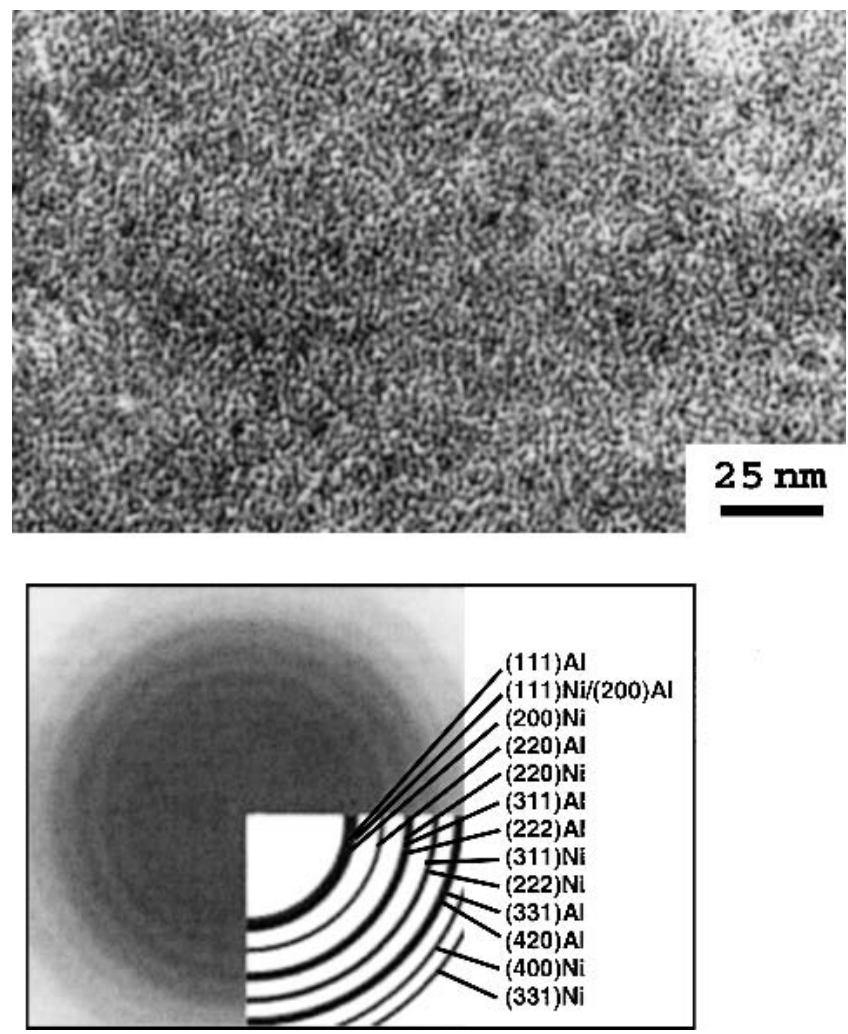

FIG. 1. Bright-field image of as-deposited thin film at room temperature. The SADP of a large area is also shown. 
the superposition of the two fcc structures of pure $\mathrm{Ni}$ and pure Al, as shown in Fig. 1. The lattice constants calculated from the two fcc structures are shown in Table I, and they agree well with the bulk values ${ }^{28}$ in pure $\mathrm{Ni}$ and pure Al. This indicates that the structure in the as-deposited state is amorphous in the long-range, but is short-range ordered into clusters of fcc $\mathrm{Ni}$ and fcc Al. The broadening of the diffraction rings into annular bands is likely to be due to the small sizes of the short-range ordered zones or atomic clusters. From the well known Scherrer formula $\beta=\lambda / t \cos \theta$, where $\lambda$ is the electron wavelength, $t$ the crystal size, and $\theta$ the diffraction angle, the crystal size calculated from the broadening of the $\{220\}_{\mathrm{Al}}$ reflection in the SADP in Fig. 1 is about $2.1 \pm 0.7 \mathrm{~nm}$, which corresponds well to the observed sizes of the black/white contrast in the bright-field image in Fig. 1. This indicates that the black/ white features in Fig. 1 are likely the images of the Ni or $\mathrm{Al}$ atomic clusters. The morphology of the as-deposited film as $\mathrm{Ni}$ and $\mathrm{Al}$ nano-clusters confirms our expectation that the cold and incompatible organic substrate limits adatom mobility during deposition. The microscopically homogeneous but nanoclustered film structure in Fig. 1 hence represents an ideal initial condition for the controlled crystallization into the desired alloy composition upon annealing.

Upon mild in situ annealing in the transmission electronic microscope at below $200{ }^{\circ} \mathrm{C}$, no observable change was observed in the structure of the film. At above $300{ }^{\circ} \mathrm{C}$, discernible changes began to take place. Figure 2(a) shows the film structure after $20 \mathrm{~min}$ at $350{ }^{\circ} \mathrm{C}$. The SADP in Fig. 2(a) exhibits only one set of diffraction rings belonging to an fcc structure, suggesting that crystallization of the as-deposited state into the $\gamma$-phase fcc solid solution has occurred. The average crystal as seen from the matrix in Fig. 2(a) is about $3 \mathrm{~nm}$. It is interesting to note that no superlattice reflections of the ordered $\mathrm{L1}_{2}$ structure can be seen in the SADP in Fig. 2(a). This indicates that crystallization of the Ni and Al clusters into an fcc structure is not accompanied by an

TABLE I. The observed lattice constants and crystal structures in $\mathrm{Ni}-\mathrm{Al}$ films and their bulk values

\begin{tabular}{lclc}
\hline \hline & $\begin{array}{c}\text { Temperature } \\
\left({ }^{\circ} \mathrm{C}\right)\end{array}$ & $\begin{array}{c}\text { Lattice } \\
\text { structure }\end{array}$ & $\begin{array}{c}\text { Lattice constant } \\
(\AA)\end{array}$ \\
\hline $\mathrm{Ni}$ (bulk) & & $\mathrm{fcc}$ & $3.52^{\mathrm{a}}$ \\
$\mathrm{Al}$ (bulk) & & $\mathrm{fcc}$ & $4.05^{\mathrm{a}}$ \\
$\mathrm{Ni}{ }_{3} \mathrm{Al}$ (bulk) & & $\mathrm{Ll}_{2}$ & $3.57^{\mathrm{a}}$ \\
$\mathrm{Ni} \mathrm{Al} \mathrm{(films)}$ & As-deposited & $\mathrm{fcc}(\mathrm{Ni})$ & 3.50 \\
& & $\mathrm{fcc}(\mathrm{Al})$ & 3.99 \\
& 150 & $\mathrm{fcc}$ & 3.87 \\
& 350 & $\mathrm{fcc}$ & 3.64 \\
& 650 & $\mathrm{Ll}_{2}$ & 3.56 \\
\hline \hline
\end{tabular}

${ }^{\mathrm{a}}$ From Ref. 28. immediate ordering into the $\mathrm{L}_{2}$ structure which is the equilibrium phase in the bulk. Ordering into the $\mathrm{L1}_{2}$ occurs above a temperature of about $500{ }^{\circ} \mathrm{C}$, as shown by the appearance of the $\{100\}$ and $\{110\}$ superlattice reflections in the SADP of Fig. 2(b) at $550{ }^{\circ} \mathrm{C}$. Higher order superlattice reflections are not clearly visible in Fig. 2(b) presumably because they are much weaker in the $\mathrm{Ni}_{3} \mathrm{Al}$ structure. The grain size in the initially ordered state is about the same as in the crystallized state. Figure 3 shows the bright-field image of another specimen annealed at $500{ }^{\circ} \mathrm{C}$ for $30 \mathrm{~min}$. Extensive abnormal grain growth had not occurred yet in the local area imaged in Fig. 3, but had occurred in other places in the specimen. The SADP of the area in Fig. 3 is in fact indistinguishable from that shown in Fig. 2(b) and is therefore not shown. It can be seen that the ordered crystallites in Fig. 3 have sizes of about approximately $3 \mathrm{~nm}$. The observed crystal structures and lattice constants as determined from SADP at various annealing temperatures are summarized in Table I.

Returning to Figs. 2(a)-2(f), which show the same area in a sample during an in situ annealing experiment, some interesting structural developments can be seen during annealing up to approximately $750{ }^{\circ} \mathrm{C}$. In Fig. 2(a) at $350{ }^{\circ} \mathrm{C}$, a few $\gamma$-phase crystals about $10 \mathrm{~nm}$ in size have abnormally grown out from the matrix of nanometersized nanocrystals. Both the nanocrystals in the matrix and the larger crystals have the same fcc structure, as indicated by the fact that a typical SADP taken over a wide area covering both the matrix and the large crystals reveal a set of diffraction rings of the fcc structure, with scattered diffraction spots lying on top of the rings. The scattered diffraction spots correspond to the larger crystals and the continuous rings to the randomly oriented nanocrystals in the matrix. In Figs. 2(b)-2(f), following ordering into the $\mathrm{L1}_{2}$ structure at above approximately $500{ }^{\circ} \mathrm{C}$, the large grains continue to grow abnormally by drawing up material from their surroundings as well as by grain coalescence, as exemplified by the pair of grains pointed at by arrows at the lower right corner of the micrograph in Fig. 2(b). The abnormal grain growth is apparently the reason for the breaking up of the matrix in Figs. 2(c)-2(f), as material is drawn to enlarge and thicken the growing grains. The flow of matter in the matrix in Figs. 2(b)-2(f) is evidently like viscous liquid flow, and this can take place presumably because of the thin condition of the film, which provides very large free surfaces and hence a large proportion of energetic atoms at the annealing temperatures concerned. Abnormally grown grains are also heavily faulted and twinned, as shown in Figs. 2(b)-2(f). "Annealing" twins are clearly observable in some of the larger grains in Figs. 2(c)-2(f). In Figs. 2(d)-2(e), the twins are merely not in diffraction contrast because of the slight rotations during thermal changes in the sample. The twinning/faulting density in the large grains in Figs. 2(c)-2(f) is very high, 

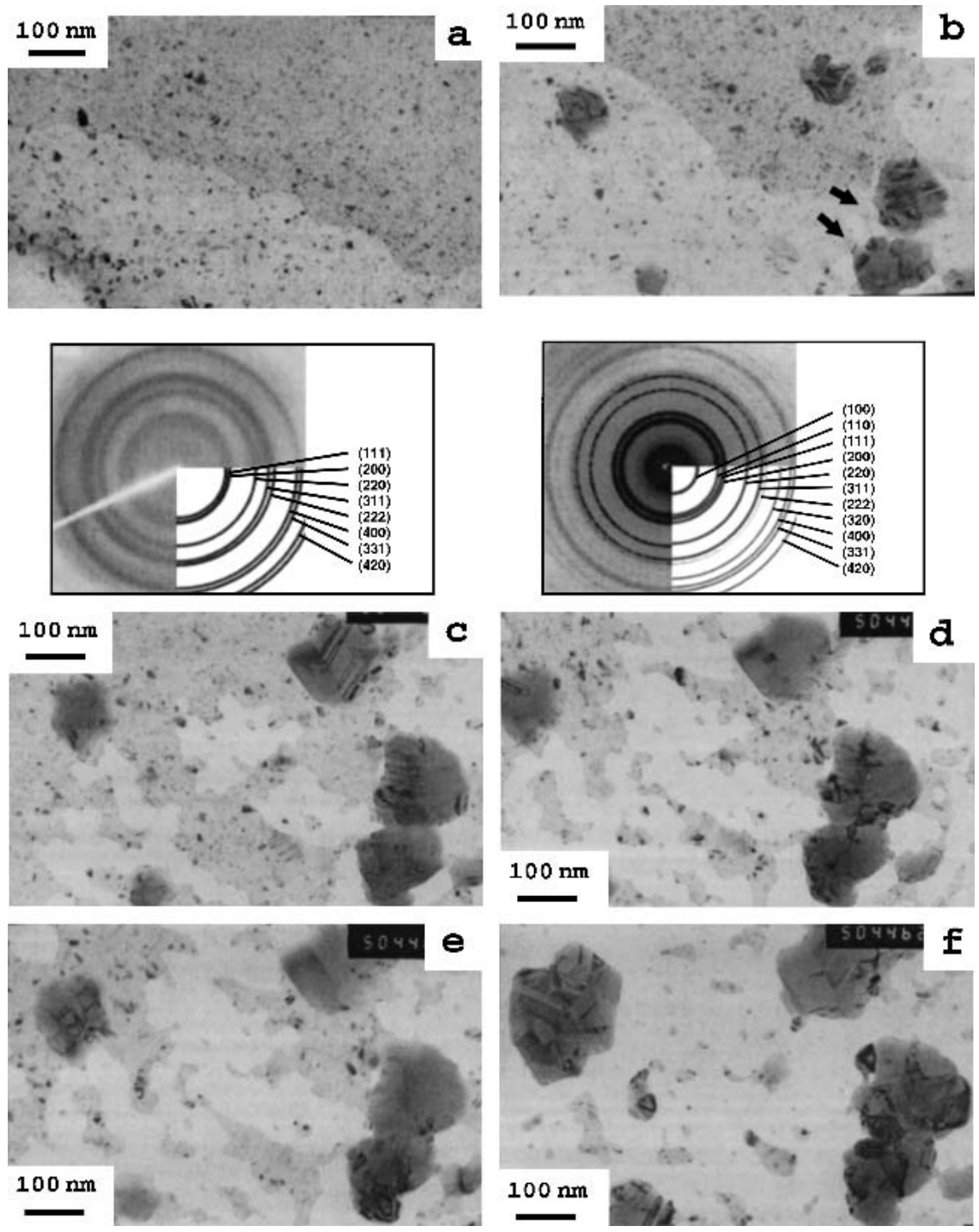

FIG. 2. Images of the same area in a sample during in situ annealing showing crystallization, abnormal grain growth, coalescence, and twinning of $\mathrm{Ni}_{3} \mathrm{Al}$ nanocrystals. (a) $350{ }^{\circ} \mathrm{C}$ for $25 \mathrm{~min}$; (b) $550{ }^{\circ} \mathrm{C}$ for $30 \mathrm{~min}$; (c) $650{ }^{\circ} \mathrm{C}$ for $20 \mathrm{~min}$; (d) $650{ }^{\circ} \mathrm{C}$ for $25 \mathrm{~min}$; (e) $750{ }^{\circ} \mathrm{C}$ for $12 \mathrm{~min}$; and (f) $750{ }^{\circ} \mathrm{C}$ for $30 \mathrm{~min}$.

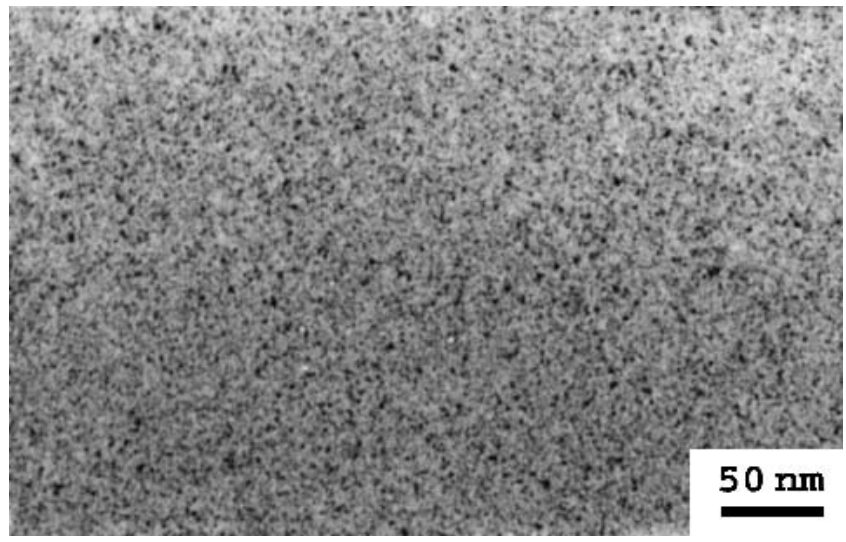

FIG. 3. Bright-field image of $\mathrm{Ni}_{3} \mathrm{Al}$ grains with size of approximately $3 \mathrm{~nm}$, synthesized using our method (after annealing at $500{ }^{\circ} \mathrm{C}$ for $30 \mathrm{~min})$. and this is likely to be a result of the coalescence process. Annealing twins and faults are known to exist in bulk $\mathrm{Ni}_{3} \mathrm{Al}^{29}$

\section{CONCLUSION}

To summarize, we have demonstrated the possibility of using co-sputtering onto cold, incompatible substrates followed by controlled heat treatment to synthesis MANCs of $\mathrm{Ni}_{3} \mathrm{Al}$. The key step is the production of a uniform but highly supercooled as-deposited state consisting of atomic clusters of $\mathrm{Ni}$ and $\mathrm{Al}$, which provides an ideal starting condition for the controlled crystallization into $\mathrm{Ni}_{3} \mathrm{Al}$ nanocrystals upon subsequent heating. A possible alternative to co-sputtering to produce an initial amorphous state would be rapid solidification. For $\mathrm{Ni}_{3} \mathrm{Al}$, 
however, no report on successful production of a glassy state by rapid solidification has ever been made, and Wang et al. ${ }^{26}$ have performed molecular dynamics simulation to demonstrate that the theoretical cooling rate required to achieve a glassy state is far too high to be reachable in experimental conditions. The co-sputtering technique here, therefore, offers a far more practical method to produce a supercooled state of any composition suitable for aging treatments.

The observed structural changes upon annealing in the current study agree fairly closely to the theoretical predictions by Wang et al. in their molecular dynamics simulation of heating from the glassy state of $\mathrm{Ni}_{3} \mathrm{Al}^{26}{ }^{26}$ We observed crystallization into the fcc $\gamma$-phase structure at about $300-350{ }^{\circ} \mathrm{C}$ from the as-deposited supercooled state, and Wang et al. predicted $410{ }^{\circ} \mathrm{C}$ to be the crystallization temperature from the glassy state. Wang et al.'s slightly higher crystallization temperature may be due to the very high heating rate of $4 \times$ $10^{11}{ }^{\circ} \mathrm{C} / \mathrm{s}$ used by them, compared to our step-wise isothermal treatment. Also, we observed no immediate ordering into the $\mathrm{L}_{2}$ structure upon crystallization, and the same was predicted by Wang et al. At the highest temperature of $527{ }^{\circ} \mathrm{C}$ simulated by Wang et al., they observed partial ordering into $\mathrm{L}_{2}$, whereas we observed ordering above a temperature of 500 to $550{ }^{\circ} \mathrm{C}$. The agreement between the two studies is therefore very good, considering the very high heating rate used by Wang et al., which is inevitable in any molecular dynamics study due to limitations on computational time.

The results here also represent an interesting contrast to a recent work by Banerjee et al., ${ }^{30}$ who have used an $\mathrm{L}_{2}$-structured $\mathrm{Ni}_{3} \mathrm{Al}$ target for sputtering onto amorphous $\mathrm{SiO}_{2}$ and $\mathrm{NaCl}(100)$ substrates, as opposed to our cotargets of pure $\mathrm{Ni}$ and $\mathrm{Al}$ plates onto organic films. On unheated substrates, Banerjee et al. observed a rather complicated metastable multiphase mixture consisting of a hexagonal close-packed Ni-rich phase and a tetragonal phase, together with a more usual fcc Ni-rich phase. The possible development of such a multiphase mixture into $\mathrm{Ni}_{3} \mathrm{Al}$ by postdeposition annealing was not followed by these authors, but the grain size of such an as-deposited state was already between 30 and $50 \mathrm{~nm}$. However, they also performed deposition on $400{ }^{\circ} \mathrm{C}$-heated substrates, and they observed monolithic $\mathrm{L}_{2}-\mathrm{Ni}_{3} \mathrm{Al}$ right away in the as-deposited state, albeit their rather large crystal sizes of about $125 \mathrm{~nm}$. Banerjee et al.'s aim was not about finding the best route for synthesizing MANCs of $\mathrm{Ni}_{3} \mathrm{Al}$, but their results nevertheless help to reveal that our current method of co-sputtering followed by postdeposition annealing, compared to sputtering directly from an $\mathrm{Ni}_{3} \mathrm{Al}$ target, offers much more control over the size of the resultant $\mathrm{Ni}_{3} \mathrm{Al}$ nanocrystals. As shown in the sequence in Figs. 2(b)-2(f), a range of grain sizes spanning from approximately $3 \mathrm{~nm}$ to over $100 \mathrm{~nm}$ can be synthesized using our method whereas no such control seems to exist if sputtering is directly from an alloy target. The grain size of approximately $3 \mathrm{~nm}$ achieved by our method is the smallest ever reported for monolithic $\mathrm{L}_{2}$-ordered $\mathrm{Ni}_{3} \mathrm{Al}$. Previous attempts to synthesize monolithic, nanocrystalline $\mathrm{Ni}_{3} \mathrm{Al}$ by sputtering ${ }^{30-32}$ or mechanical alloying ${ }^{23}$ ended up with grain sizes well over $10 \mathrm{~nm}$.

Regarding outlook, the current method should be applicable for the synthesis of a wide range of MANCs, enabling many new and exciting experiments to be conducted to investigate the properties and applications of MANCs in general. In particular, many interesting and outstanding phase equilibria issues in the nanoscale, such as the effects of nano-grain size on phase diagrams, eutectic reactions, ${ }^{33}$ martensitic transformations, ${ }^{13}$ and so forth, can all be studied by samples synthesized using this method. New material phases that are far from equilibrium in the bulk condition but may nevertheless exist in the nano-sized and supercooled conditions may also be produced this way. ${ }^{30,34}$ The nano-sized disordered $\gamma$-phase with the $\mathrm{Ni}-25$ at.\% $\mathrm{Al}$ composition at below approximately $350{ }^{\circ} \mathrm{C}$ in the current experiment is an example of these. It is expected that the current method of synthesizing MANCs will open up many exciting research opportunities in the field of materials science and nanotechnology.

\section{ACKNOWLEDGMENTS}

We thank H.P. Ng, K.L. Wang, Y.F. Chen, and N.B. Ming for their valuable assistance during the initial stages of the research. The work described in this paper was supported by a grant from the Research Grants Council of the Hong Kong Special Administrative Region, China (Project No. HKU 7077/00E).

\section{REFERENCES}

1. H. Gleiter, Acta Mater. 48, 1 (2000).

2. I.A. Ovid'ko, Science 295, 2386 (2002).

3. L. Manna, D.J. Milliron, A. Meisel, E.C. Scher, and A.P. Alivisatos, Nature Mater. 2, 382 (2003).

4. S.X. McFadden, R.S. Mishra, R.Z. Valiev, A.P. Zhilyaev, and A.K. Mukherjee, Nature 398, 684 (1999).

5. R.R. Chianelli, G. Berhault, P. Santiago, D. Mendoza, A. Espinosa, J.A. Ascencio, and M.J. Yacaman, Mater. Tech. 15, 54 (2000).

6. Y.B. Lou, M.M. Maye, L. Han, J. Luo, and C.J. Zhong, Chem. Commun. 5, 473 (2001).

7. M.E. McHenry, M.A. Willard, and D.E. Laughlin, Prog. Mater. Sci. 44, 291 (1999).

8. P. Gorria, V.M. Prida, M. Tejedor, B. Hernando, and M.L. Sanchez, Physica B 299, 215 (2001).

9. J. Petzold, Scr. Mater. 48, 895 (2003).

10. H.P. Ng and A.H.W. Ngan, J. Appl. Phy. 88, 2609 (2000). 
11. R.L. Holtz, V. Provenzano, and M.A. Imam, Nano. Mater. 7, 259 (1996).

12. Y. Saotome, K. Imai, S. Shioda, S. Shimizu, and T. Zhang, A. Inoue, Intermetallics 10, 1241 (2002).

13. V.G. Pushin, N.I. Kourov, T.E. Kuntsevich, N.N. Kuranova, N.M. Matveeva, and L.I. Yurchenko, Phys. Met. Metall. 94, S107 (2002)

14. C.Y. Wang, Y. Zhou, Y.R. Zhu, H.J. Liu, and Z.Y. Chen, Mater. Res. Bull. 35, 1463 (2000).

15. Y.B. Pithawalla, M.S. El-Shall, and S.C. Deevi, Intermetallics 8, 1225 (2000).

16. Y.B. Pithawalla, S.C. Deevi, and M.S. El-Shall, Mat. Sci. Eng. A329-331, 92 (2002).

17. K. Samwer, H.J. Fecht, and W.L. Johnson, in Glassy Metals III Amorphization Techniques, Catalysis, Electronic and Ionic Structure, edited by H. Beck and H-J. Güntherodt (Springer-Verlag, Berlin, Heidelberg, 1994), p. 5.

18. I.I. Kornilov, in Intermetallic Compounds, edited by J.H. Westbrook (John Wiley \& Sons, New York, 1967), p. 349.

19. A.H.W. Ngan, J.B. Pethica, and H.P. Ng, J. Mater. Res. 18, 382 (2003).

20. E. Ma, J. Mater. Res. 9, 592 (1994).

21. G.F. Zhou, M.J. Zwanenburg, and H. Bakker, J. Appl. Phys. 78, 3438 (1995).
22. Y.S. Cho and C.C. Koch, J. Alloy. Cmpds. 194, 287 (1993).

23. L. He and E. Ma, Mat. Sci. Eng. A, 204, 240 (1995).

24. L. Lu, M. Lai, and S. Zhang, J. Mater. Proc. Tech. 48, 683 (1995).

25. Y. Huang, M.J. Aziz, J.W. Hutchinson, A.G. Evans, R. Saha, and W.D. Nix, Acta Mater. 49, 2853 (2001).

26. L. Wang, H. Liu, K. Chen, and Z. Hu, J. Mater. Res. 13, 1497 (1998).

27. H.P. Ng, X.K. Meng, and A.H.W. Ngan, Scr. Mater. 39, 1737 (1999).

28. G. Petzow and G. Effenberg, Ternary Alloys - A Comprehensive Compendium of Evaluated Constitutional Data and Phase Diagrams, Vol. 7, (VCH, Weinheim, 1988), p. 434.

29. C. Escher, S. Neves, and G. Gottstein, in Proceedings of 3rd International Conference on Recrystallization and Related Topics, edited by T.R. McNelly (Monterey Institute of Advanced Studies, Monterey, CA, 1997), pp. 645-652.

30. R. Banerjee, G.B. Thompson, G.B. Viswanathan, and H.L. Fraser, Philos. Mag. Lett. 82, 623 (2002).

31. H.P. Ng and A.H.W. Ngan, J. Mater. Res. 17, 2085 (2002).

32. P. de Almeida, R. Schaublin, A. Almazouzi, M. Victoria, and F. Levy, Thin Solid Films 368, 26 (2000).

33. W.H. Guo and H.W. Kui, Acta Mater. 48, 2117 (2000).

34. R.Z. Valiev, Mater. Sci. Forum, 343-3, 773 (2000). 